\title{
IUFOST2006/1385 Intervention and Mobilisation for Food Security
}

\author{
A. Mcgill \\ James Martin Institute for Science and Civilization, Said Business School, Oxford University, Park End \\ Street, OX1 1HP Oxford, United Kingdom \\ albert.mcgill@sbs.ox.ac.uk
}

\begin{abstract}
"Working together to secure a safe and sufficient food supply for all" is one of IUFoST's missions right from its foundation in 1962. Appeals for practical steps based on IUFoST's possibilities have been carried at all IUFoST Congresses unfortunately with only few very modest lasting effects. In a more realistic approach it is suggested as one of several measures to improve the situation of areas hidden by food insecurity and poverty to use 'champions' or 'envoys' to distribute relevant information and initiate activities which might help to improve the desperate conditions in those areas. The quality of the information material to be distributed and used for the improvement of the desperate conditions will be the key issue to success. It is recommended that IUFoST organises working groups which compile guidelines and working recommendations for the 'champions' and 'envoys'. Parallel to the elaboration of this material practical recommendations for rural people should be developed and put on the IUFoST website. This information could be used by local "intellectuals" who have access to the internet. It is important that in this approach individual members of organisations that make up the Adhering Bodies should be mobilised in order to create a bottom up development. If that is possible it will add significantly not only to the total numbers of participants but also to the diversity of knowledge and professional ability deployed. It is also relevant for the success of the project to use local knowledge and understanding in defining the critical issues for each country or region. Simply asking each Adhering Body to respond to a request for complex and detailed information about their country is unlikely to meet with much success. Additionally, there may also be some conflict of views on such issues depending on whether the respondent works for a government research agency or a multinational food company. Even if responses come from every member country it will leave at least 82 countries with no voice or representation. It may be that neighbouring or related countries who are IUFoST members must act as "surrogates" for this project
\end{abstract}

